\title{
Downregulation of DNA-PKes suppresses P-gp expression via inhibition of the Akt/NF-кB pathway in CD133-positive osteosarcoma MG-63 cells
}

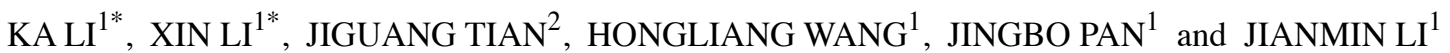 \\ Departments of ${ }^{1}$ Orthopedic Surgery and ${ }^{2}$ Emergency Surgery, Qilu Hospital, \\ Shandong University, Jinan, Shandong 250014, P.R. China
}

Received March 11, 2016; Accepted April 22, 2016

DOI: $10.3892 /$ or.2016.4991

\begin{abstract}
The development of chemoresistance is closely linked to the plateau of the survival rate in osteosarcoma (OS) patients. CD133-positive (CD133+) OS cells are known as cancer stem cells (CSCs) in OS and exhibit the characteristic of chemoresistance. In this study, $\mathrm{CD}_{13}{ }^{+}$and CD133-negative (CD133') MG-63 cells were isolated by magnetic activated cell sorting (MACS). We verified that CD133 ${ }^{+}$MG-63 cells were more resistant to cisplatin (CDDP) than CD133- MG-63 cells. DNA-dependent protein kinase catalytic subunit (DNA-PKcs) and P-glycoprotein (P-gp) were expressed at higher levels in the CD133+ MG-63 cells compared with those levels in the CD133- MG-63 cells, whereas downregulation of DNA-PKcs by small interfering RNA (siRNA) decreased chemoresistance to CDDP and P-gp expression at the mRNA and protein levels in these cells. This indicated that DNA-PKcs was correlated with P-gp expression in the $\mathrm{CD}_{133^{+}} \mathrm{MG}-63$ cells. The Akt/NF- $\mathrm{KB}$ pathway was hyperactivated in the $\mathrm{CD} 133^{+} \mathrm{MG}-63$ cells, whereas inhibition of the Akt/NF- $\kappa \mathrm{B}$ pathway downregulated P-gp expression. In addition, downregulation of DNA-PKcs suppressed the activity of the Akt/NF- $\mathrm{B}$ pathway. These results revealed that downregulation of DNA-PKcs could decrease P-gp expression via suppression of the $\mathrm{Akt} / \mathrm{NF}-\kappa \mathrm{B}$ pathway in $\mathrm{CD} 133^{+}$ MG-63 cells. Therefore, inhibition of DNA-PKcs decreases P-gp expression and sensitizes OS CSCs to chemotherapeutic agents in vitro, which needs to be further validated in vivo.
\end{abstract}

Correspondence to: Professor Jianmin Li, Department of Orthopedic Surgery, Qilu Hospital, Shandong University, 107 Wenhua Xi Road, Jinan, Shandong 250014, P.R. China

E-mail: qlgkjmli@163.com

"Contributed equally

Key words: osteosarcoma, DNA-dependent protein kinase catalytic subunit, P-glycoprotein, cancer stem cells, Akt/NF- $\kappa \mathrm{B}$ pathway, drug resistance

\section{Introduction}

Osteosarcoma (OS) is the most common primary solid tumor of bone in children and adolescence among various types of bone tumors (1). With the introduction of chemotherapy in the 1970 's, the 5-year survival rate after surgery has increased to $50-70 \%$ in patients without metastasis (2-4). However, there has been no further improvement during the last three decades in terms of the survival rate and it remains at $20-30 \%$ for patients with detectable metastasis $(4,5)$. The development of chemoresistance in OS contributes to the plateau of the survival rate to a certain extent. It is necessary to investigate the mechanisms of OS drug resistance.

The cancer stem cell (CSC) model is one emerging model for the development of drug resistance in malignancies. CSCs markedly promote drug resistance in various cancers (6). It has been demonstrated that CD133-positive (CD133+) cells in OS exhibit CSC characteristics (7-9). However, the mechanisms of drug resistance in $\mathrm{CD}_{133}{ }^{+} \mathrm{OS}$ cells need to be further elucidated.

DNA-dependent protein kinase catalytic subunit (DNA-PKcs) is a member of the large phosphatidylinositol 3-kinase (PI3K)-related kinase (PIKK) family. DNA-PKcs, along with accessory heterodimeric complexes, Ku70 and $\mathrm{Ku} 80$, are involved in DNA damage repair via non-homologous end joining (NHEJ). Our previous studies revealed that inhibition of DNA-PKcs sensitized OS cells to chemotherapeutic agents (10), indicating that DNA-PKcs plays a significant role in chemoresistance. Moreover, DNA-PKcs was found to be overexpressed in OS CSCs (11), which might be one of the causes of chemoresistance in OS.

P-glycoprotein (P-gp), a member of the ATP-binding cassette $(\mathrm{ABC})$ transporters, is encoded by the ABCB1 gene and plays an important role in chemoresistance in tumors. Hence, it is necessary to understand the mechanisms of the regulation of P-gp. It has been demonstrated that P-gp expression is at a higher level in OS CSCs compared with that in non-CSCs (9). Although DNA-PKcs and P-gp are involved in chemoresistance and are overexpressed in OS CSCs, there has been no study concerning the relationship between DNA-PKcs and P-gp in OS CSCs to date. Previous studies have revealed that the expression of $\mathrm{P}-\mathrm{gp}$ is regulated by the $\mathrm{PI} 3 \mathrm{~K} / \mathrm{Akt} / \mathrm{NF}-\kappa \mathrm{B}$ 
pathway in other cancers $(12,13)$. This prompted us to investigate the relationship between DNA-PKcs and P-gp in OS CSCs, as well as the role of the Akt/NF- $\kappa$ B pathway in this relationship.

We hypothesize that DNA-PKcs regulates P-gp via the $\mathrm{Akt} / \mathrm{NF}-\mathrm{\kappa B}$ axis in $\mathrm{CD} 133^{+} \mathrm{OS}$ cells. The purpose of this study was to investigate the role of DNA-PKcs in P-gp expression and the underlying molecular mechanism in drug-resistant CD133 ${ }^{+}$ MG-63 cells. Compared with CD133-negative (CD133-) MG-63 cells, CD133 ${ }^{+}$MG-63 cells showed increased expressions of DNA-PKcs and P-gp, as well as higher activity of the $\mathrm{Akt} / \mathrm{NF}-\kappa \mathrm{B}$ pathway. Downregulation of DNA-PKcs significantly decreased the P-gp expression and activity of the $\mathrm{Akt} / \mathrm{NF}-\kappa \mathrm{B}$ pathway, and inhibition of the Akt/NF- $\mathrm{B}$ pathway downregulated the P-gp expression. All of these results revealed that DNA-PKcs regulates $\mathrm{P}-\mathrm{gp}$ via the $\mathrm{Akt} / \mathrm{NF}-\kappa \mathrm{B}$ pathway in $\mathrm{CD} 133^{+}$OS cells.

\section{Materials and methods}

Cell culture. The human MG-63 cell line was purchased from the American Type Culture Collection (ATCC; Manassas, VA, USA). Cells were cultured in Dulbecco's minimal essential medium (DMEM) supplemented with $10 \%$ fetal bovine serum (both from Gibco, Grand Island, NY, USA) at $37^{\circ} \mathrm{C}$, with $5 \% \mathrm{CO}_{2}$ in a $95 \%$ humidified atmosphere.

Magnetic activated cell sorting (MACS). MACS was performed using CD133 MicroBead kit (Miltenyi Biotec, Auburn, CA, USA) following the manufacturer's instructions. Briefly, a single-cell suspension was prepared in the MACS separation buffer. Cells were incubated with FcR Blocking Reagent and CD133 MicroBeads at $4^{\circ} \mathrm{C}$ for 15 min. After washing steps, magnetic separation was performed using an LS Column and MACS Separator (Miltenyi Biotec). The magnetically labeled $\mathrm{CD}_{133^{+}}$cells and unlabeled CD133- cells were collected, respectively.

Cell viability assay. Cells were seeded in 96-well plates at a density of 5,000 cells/well. Then cisplatin (CDDP; Qilu Pharmaceutical Co., Ltd., Shandong, China) was added at increasing concentrations. Survival of the cells was measured $24 \mathrm{~h}$ post-treatment using the Cell Counting Kit-8 (CCK-8; BestBio, Shanghai, China) according to the manufacturer's instructions. The cell survival rate was presented as the percentage of viable cells compared with the corresponding viable cells in the drug-free controls. The half maximal inhibitory concentration $\left(\mathrm{IC}_{50}\right)$ was calculated from the relative survival curve.

Transfection of small interfering RNA (siRNA) and inhibitor treatment. The $\mathrm{CD}_{133}{ }^{+} \mathrm{MG}-63$ cells were seeded into ultra-low attachment 6-well plates in serum-free medium. The serum-free medium consisted of Dulbecco's modified Eagle's medium (DMEM), $20 \mathrm{ng} / \mathrm{ml}$ epidermal growth factor (EGF), $20 \mathrm{ng} / \mathrm{ml}$ basic fibroblast growth factor (bFGF) (both from PeproTech, Rocky Hill, NJ, USA) and N-2 Supplement (Gibco). For siRNA transfection, the siDNA-PKcs, siNF- $\kappa \mathrm{B} / \mathrm{p} 65$ or control siRNAs (GenePharma Co., Ltd., Shanghai, China) were transfected into the cells using Lipofectamine 2000 (Invitrogen,
Carlsbad, CA, USA) according to the manufacturer's instructions. After 24 or $48 \mathrm{~h}$ of transfection, the cells were harvested for further experiments at the gene or protein level, respectively. For the inhibition experiment, the CD133+ MG-63 cells were treated with Akt inhibitor MK-2206 2HCl $(10 \mu \mathrm{M})$ (Selleck, Houston, TX, USA) for $24 \mathrm{~h}$, and subjected to gene and protein expression experiments.

Immunofluorescence. The cells were seeded on 24-well chamber slides. After adherence, the cells were fixed with $4 \%$ paraformaldehyde for $15 \mathrm{~min}$. The fixed cells were incubated in $0.3 \%$ Triton X-100 for 10 min to permeabilize and $10 \%$ normal goat serum for $1 \mathrm{~h}$ to block non-specific protein-protein interactions. Then the cells were incubated with the rabbit polyclonal anti-human P-gp (ab129450, 1:200) and mouse monoclonal anti-human DNA-PKcs primary antibodies (ab1832, 1:100) (both from Abcam, Cambridge, MA, USA) overnight at $4^{\circ} \mathrm{C}$. The Alexa Fluor 488 goat anti-rabbit (ZF-0511, 1:200) and Alexa Fluor 594 goat anti-mouse (ZF-0513, 1:200) (both from Beijing Zhongshan Golden Bridge Biotechnology Co., Ltd., Beijing, China) secondary antibodies were used for detection. 4',6-Diamidino-2-phenylindole was used to stain the cell nuclei for $5 \mathrm{~min}$ at room temperature. Slides were observed on an inverted fluorescence microscope (BX52; Olympus Corp., Tokyo, Japan).

Quantitative real-time polymerase chain reaction ( $q P C R)$. Total RNA was extracted with TRIzol lysis buffer (Toyobo, Osaka, Japan) according to the manufacturer's instructions. First-strand complementary DNA (cDNA) synthesis was carried out using ReverTra Ace qPCR RT kit (Toyobo). Briefly, $1 \mu \mathrm{g}$ of total RNA was used in a total volume of $10 \mu \mathrm{l}$ containing $2 \mu \mathrm{l}$ 5X RT buffer, $0.5 \mu \mathrm{l}$ RT Enzyme Mix, $0.5 \mu \mathrm{l}$ Primer Mix and nuclease-free water. The reverse transcription was performed in a thermal cycler (TGradient 96; Biometra $\mathrm{GmbH}$, Göttingen, Germany) with a temperature cycling program of $15 \mathrm{~min}$ at $37^{\circ} \mathrm{C}, 5 \mathrm{~min}$ at $98^{\circ} \mathrm{C}$. The cDNAs were used as templates for PCR amplification using SYBR ${ }^{\circledR}$ Green Realtime PCR Master Mix kit (Toyobo). In brief, reaction mixtures $(20 \mu \mathrm{l})$ for PCR were assembled using $2 \mu \mathrm{l}$ cDNA template, $6.4 \mu \mathrm{l}$ distilled water, $10 \mu \mathrm{l} 2 \mathrm{X} \mathrm{SYBR}^{\circledR}$ Green Realtime PCR Master Mix, $0.8 \mu$ l forward primers $(10 \mu \mathrm{M})$ and $0.8 \mu \mathrm{l}$ reverse primers $(10 \mu \mathrm{M})$. The cycle parameters were $95^{\circ} \mathrm{C}$ for $30 \mathrm{sec}$ followed by 40 cycles at $95^{\circ} \mathrm{C}$ for $5 \mathrm{sec}$, $55^{\circ} \mathrm{C}$ for $10 \mathrm{sec}$ and $72^{\circ} \mathrm{C}$ for $15 \mathrm{sec}$. The human GAPDH PCR product was used as an internal control. The results were standardized with the formula: $\Delta \mathrm{CT}=\mathrm{CT}_{\text {target }}-\mathrm{CT}_{\text {control }}$ and further converted to the fold of the target gene over the control gene $\left(2^{-\Delta \mathrm{CT}}\right)$. The primer sequences of the genes used in this study are presented in Table I.

Western blot analysis. The cells were harvested and total proteins were extracted with RIPA lysis buffer, and the protein concentrations were quantified with the Enhanced BCA Protein Assay kit (both from Beyotime, Shanghai, China). Equal amounts of protein were separated by sodium dodecyl sulfate-polyacrylamide gel electrophoresis (SDS-PAGE) and electroblotted onto a polyvinylidene fluoride (PVDF) membrane. Non-specific sites were blocked for $1.5 \mathrm{~h}$ with $5 \%$ non-fat milk in Tris-buffered saline and Tween-20 (TBST) 

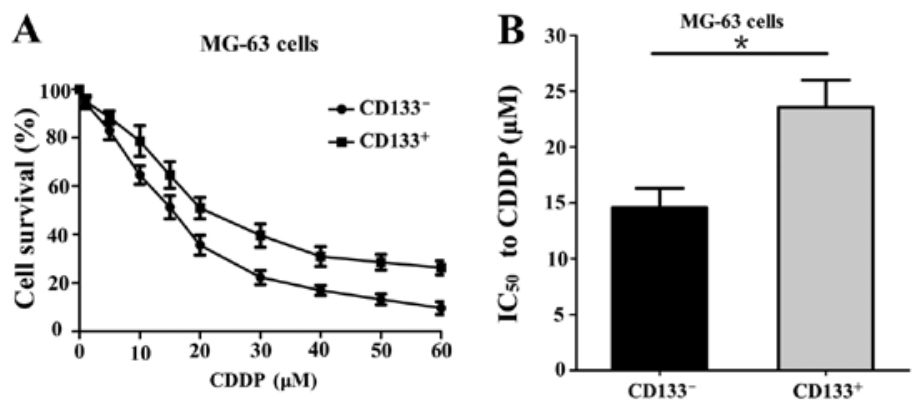

C
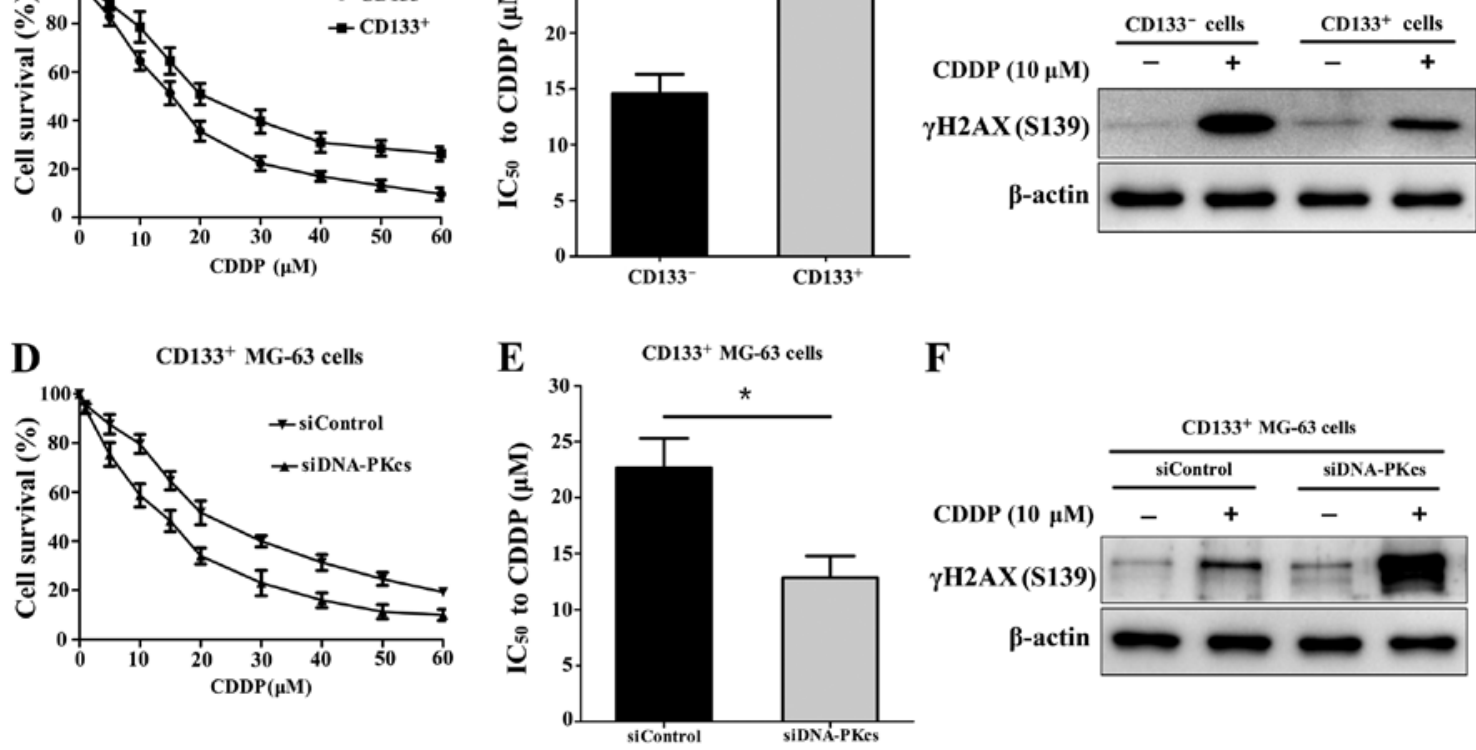

F

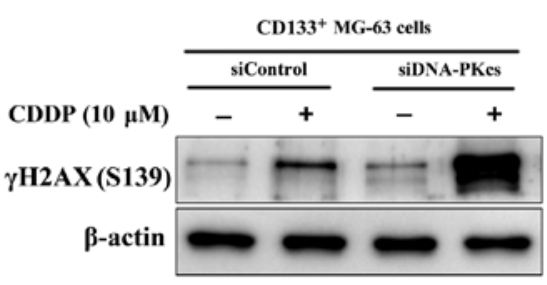

Figure 1. Downregulation of DNA-PKcs sensitizes CD133 ${ }^{+}$MG-63 cells to CDDP. (A and B) CD133+ MG-63 cells were more resistant to CDDP and had a higher $\mathrm{IC}_{50}$ value than the CD133- MG-63 cells. (C) After CDDP $(10 \mu \mathrm{M})$ treatment for $24 \mathrm{~h}$, the expression of $\gamma \mathrm{H} 2 \mathrm{AX}$ (S139) in the CD133+ cells was much lower than that in the CD133 cells. (D and E) Downregulation of DNA-PKcs by siRNA decreases the resistance to CDDP and the $\mathrm{IC}_{50} \mathrm{value}^{-}$in the CD133 MG-63 cells, and (F) increased the expression of $\gamma \mathrm{H} 2 \mathrm{AX}$ (S139) after CDDP $(10 \mu \mathrm{M})$ treatment for $24 \mathrm{~h}$. The results represent the mean \pm SD of three independent experiments; ${ }^{*} \mathrm{P}<0.05$. DNA-PKcs, DNA-dependent protein kinase catalytic subunit; CD133+, CD133-positive; CDDP, cisplatin; CD133-, CD133-negative; siRNA, small interfering RNA; SD, standard deviation.

Table I. Primer sequences for qPCR.

Primers $\left(5^{\prime}-3^{\prime}\right)$

$\begin{array}{ll}\text { PRKDC } & \text { F ACAGAGATCCAGAAAGTGAGACA } \\ & \text { R AGCAACCGGTCCAAGGTATT } \\ \text { ABCB1 } & \text { F ACAGAGGGGATGGTCAGTGT } \\ & \text { R TCACGGCCATAGCGAATGTT } \\ \text { GAPDH } & \text { F CAGGAGGCATTGCTGATGAT } \\ & \text { R GAAGGCTGGGGCTCATTT }\end{array}$

qPCR, quantitative real-time polymerase chain reaction; F, forward; $\mathrm{R}$, reverse.

at room temperature. The PVDF membranes were incubated at $4{ }^{\circ} \mathrm{C}$ overnight with primary antibodies. Primary antibodies included: rabbit polyclonal anti-human $\gamma \mathrm{H} 2 \mathrm{AX}$ (S139) (ab2893, 1:1,000), rabbit polyclonal anti-human DNA-PKcs (ab230, 1:2,000), rabbit polyclonal anti-human P-gp (ab129450, 1:1,000) antibodies from Abcam; rabbit polyclonal anti-human Akt (9272S, 1:1,000), rabbit polyclonal anti-human phospho-Akt (S473) (9271S, 1:1,000), mouse monoclonal anti-human phospho-IкB- $\alpha$ (9246S, 1:1,000), and rabbit monoclonal anti-human phospho-NF- $\kappa \mathrm{B} / \mathrm{p} 65$ (3033S, 1:1,000) antibodies from Cell Signaling Technology (Danvers, MA, USA); rabbit polyclonal anti-human phospho-Akt (T308) (sc-16646-R, 1:100), rabbit polyclonal anti-human inhibitor of $\kappa \mathrm{B}(\mathrm{I \kappa B})-\alpha(\mathrm{sc}-371,1: 100)$ antibodies from Santa Cruz Biotechnology (Dallas, TX, USA); rabbit polyclonal

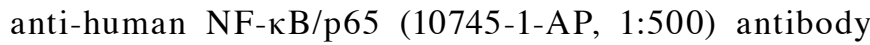
from Proteintech (Chicago, IL, USA); mouse monoclonal anti-human $\beta$-actin (TA-90, 1:500) antibody from Beijing Zhongshan Golden Bridge Biotechnology Co., Ltd. After washing with TBST, membranes were incubated with goat anti-rabbit secondary antibody (ZB-2301, 1:5,000) or goat anti-mouse secondary antibody (ZB-2305, 1:5,000) (both from Beijing Zhongshan Golden Bridge Biotechnology Co., Ltd.) conjugated with horseradish peroxidase for $1.5 \mathrm{~h}$ at room temperature. Immunoreactive bands were detected by enhanced chemiluminescence substrate (EMD Millipore, Billerica, MA, USA).

Statistical analysis. Each experiment was performed three times independently. Data are expressed as means \pm standard deviation (SD). Student's t-test was used for comparisons. Differences were considered statistically significant if $\mathrm{P}<0.05$. Statistical analysis was carried out using GraphPad Prism 5.0 (GraphPad Software, Inc., La Jolla, CA, USA).

\section{Results}

$C D 133^{+} M G-63$ cells are more resistant to $C D D P$ compared with CD133-MG-63 cells. After MACS, the CD133+ and CD133 cells were treated with CDDP at different concentrations for $24 \mathrm{~h}$, respectively. The cell viability was measured and the result showed that the $\mathrm{CD}_{133^{+}}$cells were more resistant to CDDP (Fig. 1A). The $\mathrm{IC}_{50}$ value of the $\mathrm{CD} 133^{+}$ cells was significantly higher than that of the CD133- cells (23.55 vs. $14.57 \mu \mathrm{M} ; \mathrm{P}<0.05$ ) (Fig. 1B). In addition, the expression of DNA double-strand break (DSB) marker $\gamma \mathrm{H} 2 \mathrm{AX}$ 

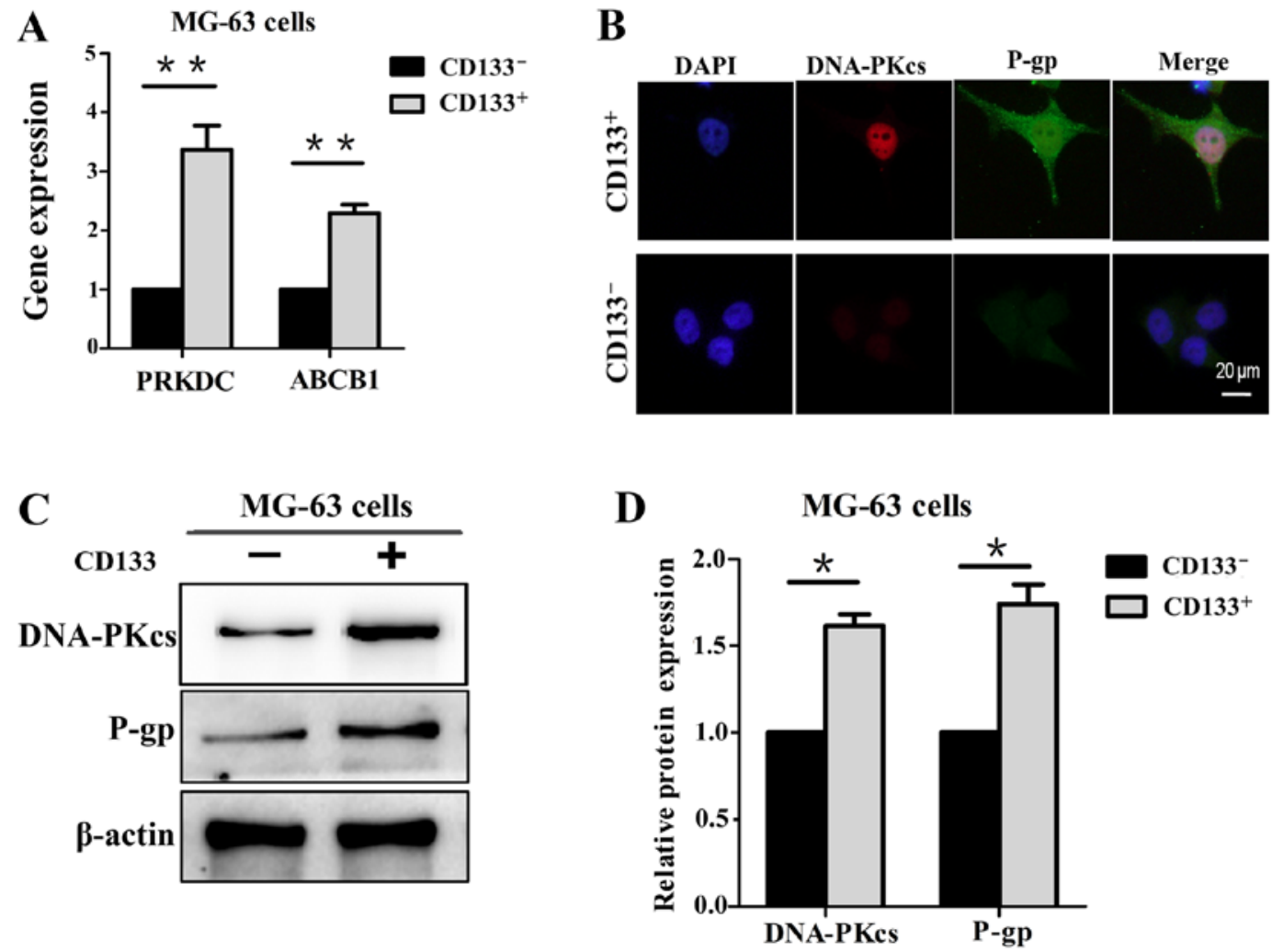

Figure 2. DNA-PKcs and P-gp are markedly elevated in the CD133+ MG-63 cells compared with levels in the CD133- MG-63 cells. (A) The expression levels of PRKDC and ABCB1 genes were significantly higher in the CD133 ${ }^{+}$MG-63 cells than levels in the CD133- MG-63 cells. (B) Immunofluorescence and (C and D) western blot analysis showed higher levels of DNA-PKcs and P-gp in the CD133+ MG-63 cells compared with levels in the CD133- MG-63 cells The results represent the mean \pm SD of three independent experiments; ${ }^{*} \mathrm{P}<0.05,{ }^{* *} \mathrm{P}<0.01$. DNA-PKcs, DNA-dependent protein kinase catalytic subunit (or PRKDC); P-gp, P-glycoprotein; CD133', CD133-positive; CD133, CD133-negative; SD, standard deviation.
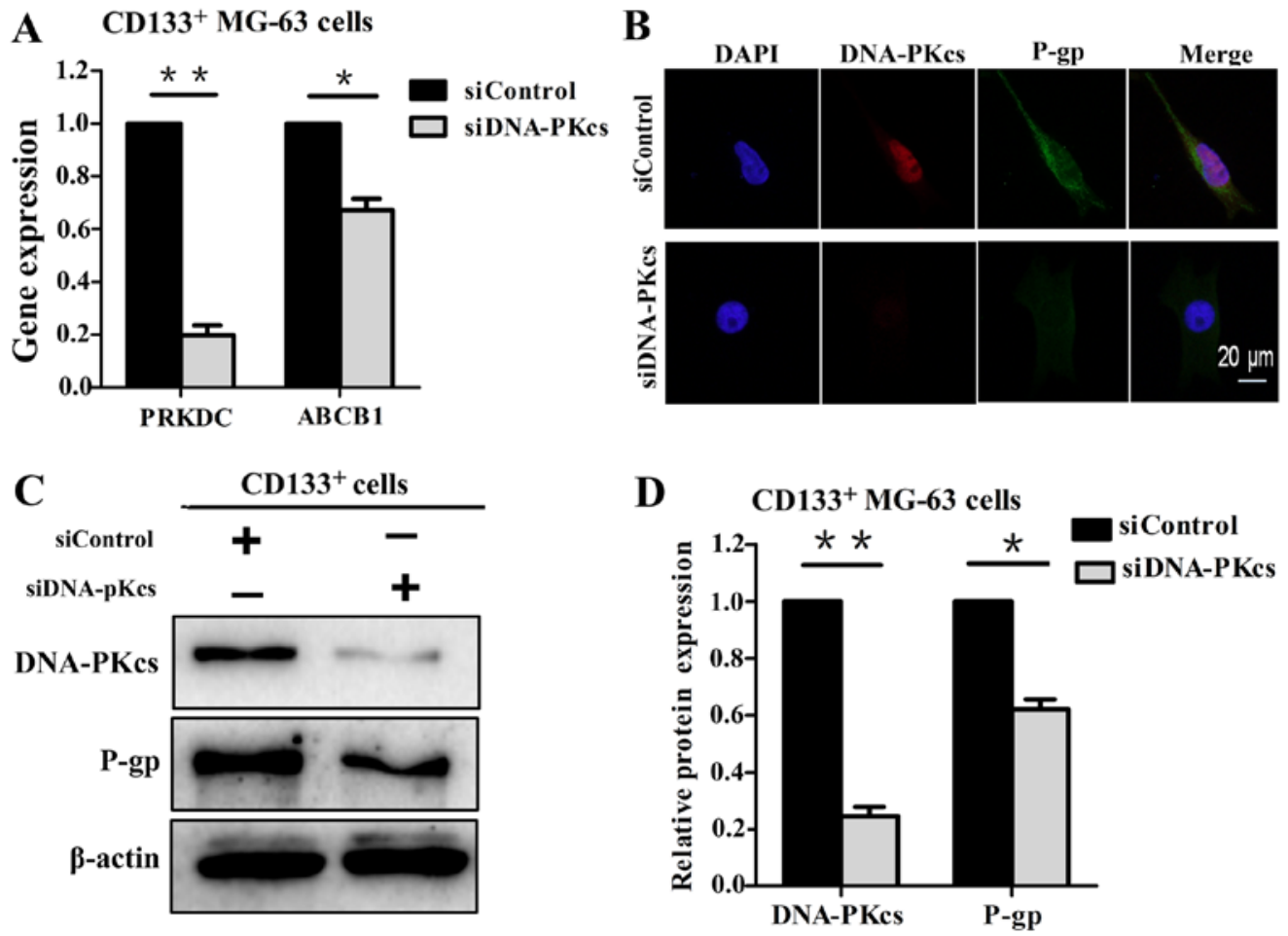

Figure 3. Downregulation of DNA-PKcs decreases P-gp expression at the gene and protein levels. (A) The expression level of the ABCB1 gene assessed by qPCR was significantly reduced in the CD133 ${ }^{+}$MG-63 cells transfected with siDNA-PKcs. (B) Immunofluorescence and (C and D) western blot analysis showed that P-gp expression was decreased in the CD133 ${ }^{+}$MG-63 cells after transfection with siDNA-PKcs. The results represent the mean \pm SD of three independent experiments; ${ }^{*} \mathrm{P}<0.05,{ }^{* *} \mathrm{P}<0.01$. DNA-PKcs, DNA-dependent protein kinase catalytic subunit (or PRKDC); P-gp, P-glycoprotein; qPCR, quantitative real-time polymerase chain reaction; $\mathrm{CD} 133^{+}, \mathrm{CD} 133$-positive; SD, standard deviation. 

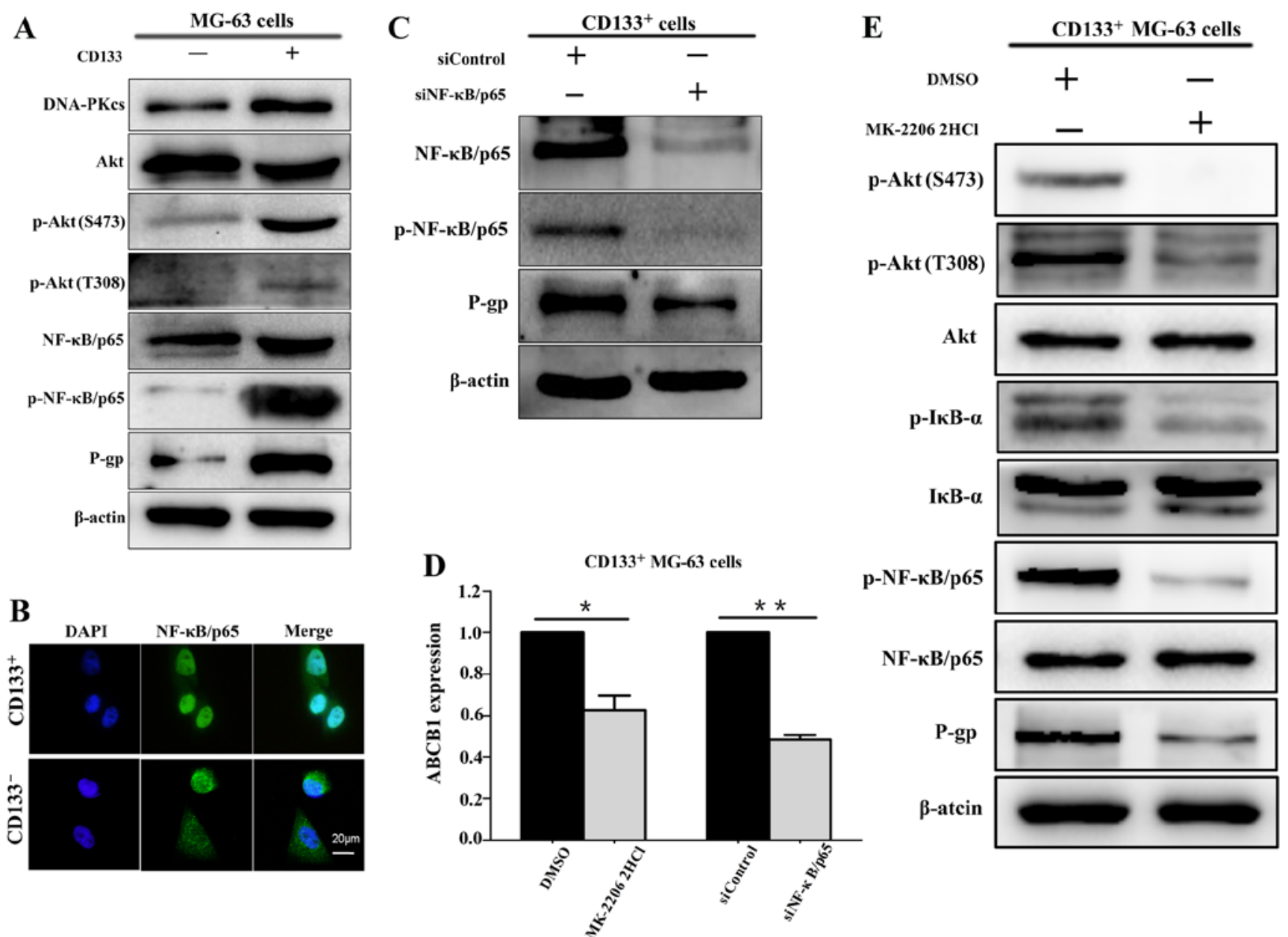

Figure 4. The Akt/NF-kB pathway is implicated in P-gp expression in the CD133+ MG-63 cells. (A) CD133+ MG-63 cells showed higher levels of p-Akt (S473 and T308), p-NF- $\mathrm{kB} / \mathrm{p} 65$ and P-gp compared with levels in the CD133- MG-63 cells. (B) NF- $\mathrm{kB} / \mathrm{p} 65$ was mainly localized in the nuclei of the CD133 ${ }^{+}$ MG-63 cells and in the cytoplasm of the CD133- MG-63 cells. (C and D) The expression levels of the ABCB1 gene and P-gp were significantly decreased after downregulation of NF- $\mathrm{kB} / \mathrm{p} 65$. (D and E) The expression levels of p-NF- $\mathrm{kB} / \mathrm{p} 65$ and P-gp, as well as the ABCB1 gene were downregulated following the inhibition of the activity of Akt by MK-2206 $2 \mathrm{HCl}(10 \mu \mathrm{M})$. The results represent the mean $\pm \mathrm{SD}$ of three independent experiments; ${ }^{*} \mathrm{P}<0.05$, ${ }^{* *} \mathrm{P}<0.01$. P-gp, P-glycoprotein; CD133 ${ }^{+}$, CD133-positive; CD133, CD133-negative; SD, standard deviation.

(S139) in the $\mathrm{CD}_{133^{+}}$cells was lower than that in the CD133 cells after CDDP $(10 \mu \mathrm{M})$ treatment for $24 \mathrm{~h}$ (Fig. 1C).

Downregulation of DNA-PKcs sensitizes $C D 133^{+} M G-63$ cells to $C D D P$. After transfection with siDNA-PKcs or siControl, the $\mathrm{CD} 133^{+}$MG-63 cells were treated with CDDP at different concentrations for $24 \mathrm{~h}$. It was shown that the CD133+ MG-63 cells with transfection of siDNA-PKcs were more sensitive to CDDP compared with the $\mathrm{CD} 133^{+}$cells transfected with the siControl (Fig. 1D). The $\mathrm{IC}_{50}$ value of the siDNA-PKcs group was lower than that of the siControl group (12.83 vs. $22.67 \mu \mathrm{M}$; $\mathrm{P}<0.05$ ) (Fig. 1E). The expression of $\gamma \mathrm{H} 2 \mathrm{AX}$ (S139) was markedly elevated in the CD133+ ${ }^{+}$MG-63 cells with siDNA-PKcs transfection after CDDP $(10 \mu \mathrm{M})$ treatment (Fig. 1F). The results revealed that downregulation of DNA-PKcs reduced the DNA damage repair and increased the sensitivity to CDDP in the $\mathrm{CD} 133^{+}$MG- 63 cells.

$D N A-P K c s$ is involved in the expression of $P$-gp. The expression level of DNA-PKcs and P-gp were first investigated in the $\mathrm{CD} 33^{+}$and CD133- MG-63 cells, respectively. The results of qPCR revealed that the PRKDC and ABCB1 genes were at higher levels in the CD133+ MG-63 cells (Fig. 2A). In addition, immunofluorescence and western blot analysis showed that the expression levels of DNA-PKcs and P-gp were elevated in the $\mathrm{CD} 133^{+}$cells compared with levels in the CD133 cells (Fig. 2B-D).

Then the CD133+ MG-63 cells were transfected with siDNA-PKcs, and P-gp was examined at the gene and protein levels. It was shown that the ABCB1 gene (Fig. 3A) and P-gp (Fig. 3B-D) expression were significantly decreased following the downregulation of DNA-PKcs. Taken together, the results indicate that DNA-PKcs is involved in P-gp expression, and DNA-PKcs and P-gp are positively correlated with chemoresistance to CDDP in CD133 ${ }^{+}$MG-63 cells.

The Akt/NF- $\kappa B$ pathway is implicated in P-gp expression in CD133+ MG-63 cells. The expression levels of p-Akt (both S473 and T308) and p-NF- $\mathrm{BB} / \mathrm{p} 65$ were examined in both the CD133+ and CD133- MG-63 cells. The results showed that p-Akt (S473), p-Akt (T308) and p-NF-kB/p65 were expressed at higher levels in the CD133 ${ }^{+}$MG-63 cells compared with these levels in the CD133- MG-63 cells (Fig. 4A). Immunofluorescence showed that NF- $\kappa \mathrm{B} / \mathrm{p} 65$ was mainly 


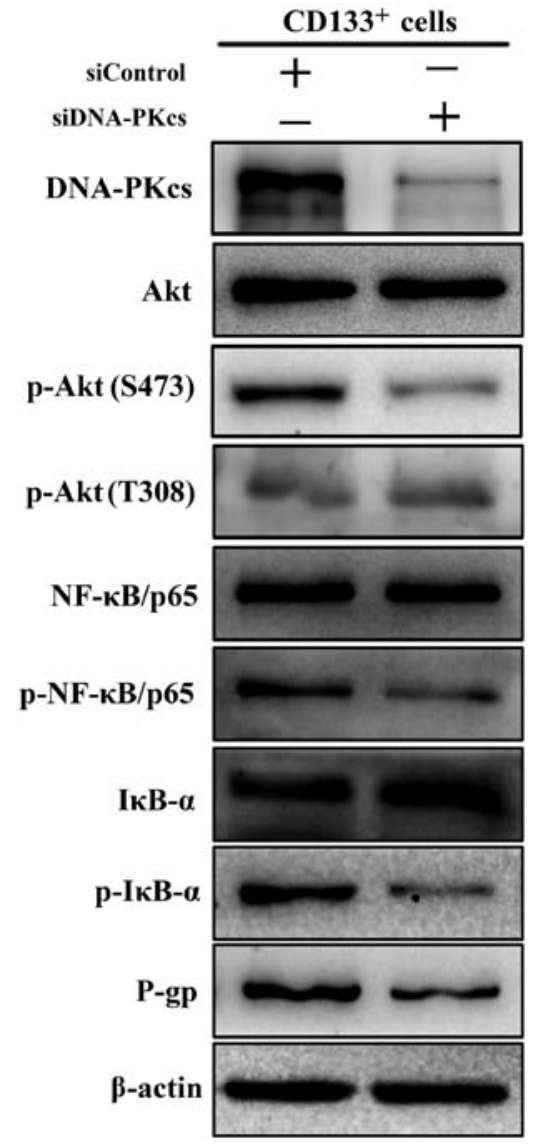

Figure 5. Downregulation of DNA-PKcs suppresses the activity of the Akt/NF-kB pathway. The expression levels of p-Akt (S473), p-NF-kB/p65, $\mathrm{p}-\mathrm{I} \kappa \mathrm{B}-\alpha, \mathrm{P}-\mathrm{gp}$, but not $\mathrm{p}$-Akt (T308), were decreased following the downregulation of DNA-PKcs. DNA-PKcs, DNA-dependent protein kinase catalytic subunit; P-gp, P-glycoprotein; ІкB, inhibitor of $\kappa B$.

localized in the nuclei of CD133+ MG-63 cells (Fig. 4B). These results indicate that $\mathrm{CD} 133^{+}$MG-63 cells display hyperactivation of the Akt/NF- $\mathrm{kB}$ pathway.

Moreover, the results showed that P-gp and ABCB1 gene expression levels were decreased following the downregulation

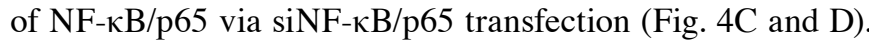
This suggests that $\mathrm{NF}-\kappa \mathrm{B} / \mathrm{p} 65$ is involved in P-gp expression. Following Akt inhibitor MK-2206 $2 \mathrm{HCl}(10 \mu \mathrm{M})$ treatment, the activity of NF- $\kappa \mathrm{B} / \mathrm{p} 65$ and expression levels of P-gp and ABCB1 genes in the CD133+ MG-63 cells were examined. It was shown that the expression levels of $\mathrm{p}-\mathrm{NF}-\mathrm{\kappa B} / \mathrm{p} 65$ and P-gp, as well as the $\mathrm{ABCB} 1$ gene were downregulated by inhibition of the activity of Akt (Fig. 4D and E).

The results above demonstrated that the Akt/NF- $\mathrm{KB}$ pathway is implicated in P-gp expression at the gene and protein levels.

Downregulation of DNA-PKcs decreases the activation of the Akt/NF- $\kappa B$ pathway in $C D 133^{+} M G-63$ cells. The Akt/NF- $\mathrm{BB}$ pathway proteins were observed in the $\mathrm{CD} 133^{+}$MG-63 cells after siDNA-PKcs transfection. Inhibition of DNA-PKcs via siDNA-PKcs decreased the expression of p-Akt (S473), p-IкB- $\alpha$, $\mathrm{p}-\mathrm{NF}-\mathrm{kB} / \mathrm{p} 65$, as well as P-gp (Fig. 5). It is worth noting that the expression of p-Akt (T308) was consistent between the siDNA-PKcs and siControl group. These results revealed that downregulation of DNA-PKcs suppressed Akt/NF- $\kappa$ B pathway activation and P-gp expression in the CD133 ${ }^{+}$MG- 63 cells.

Taken together, all the results above revealed that downregulation of DNA-PKcs decreased P-gp expression via suppression of the Akt/NF-kB pathway in the CD133 ${ }^{+}$MG-63 cells.

\section{Discussion}

It is well known that a tumor is populated by heterogeneous cell populations and drug-resistant clones exist within the tumor $(14,15)$. Targeting drug-resistant cells could have significance in the treatment of OS. The CSC theory believes that CSCs are relatively resistant to chemotherapeutic agents. Therefore, if it was possible to target drug-resistant CSCs, this would improve the therapeutic outcomes of OS. It has been well established that $\mathrm{CD} 133^{+}$cells in OS display features of CSCs (7-9), thus CD133+ MG-63 cells were taken as the object of this study.

Some chemotherapeutic reagents lead to DNA DSBs which are lethal for tumor cells. However, DSBs can be repaired by two main pathways, homologous recombination and NHEJ. DNA-PKcs, along with Ku70 and Ku80, are essential in DNA damage repair via NHEJ. Overexpression of DNA-PKcs is found in various malignancies, which is associated with poor prognosis $(16,17)$. However, inhibition of DNA-PKcs sensitizes cells to chemotherapy in various tumor cells including OS $(10,18,19)$. This indicates that DNA-PKcs is correlated with chemoresistance in tumors. Studies have revealed that DNA-PKcs is overexpressed in CSCs $(11,20)$. In this study, we found that CD133 ${ }^{+}$MG- 63 cells displayed overexpression of DNA-PKcs and chemoresistance to CDDP, along with lower expression of $\gamma \mathrm{H} 2 \mathrm{AX}$ (S139) after CDDP treatment, whereas downregulation of DNA-PKcs increased DSBs after CDDP treatment and sensitivity to CDDP. This demonstrates that DNA-PKcs overexpression leads to enhanced DNA damage repair and is involved in increased chemoresistance in OS CSCs.

The ABC family of drug transporters contributes to resistance to chemotherapeutic agents when overexpressed in tumors. P-gp is a well-characterized member of the ABC membrane transporters which functions as a drug efflux pump and reduces intracellular drug concentrations (21). Increased expression of P-gp is one of the key causes of drug resistance in tumors. Studies have reported that inhibition of P-gp reversed drug resistance in OS (22-24). Previous data revealed that high expression of P-gp is present in OS CSCs and is considered as one of the mechanisms of drug resistance in OS $(25,26)$.

The results of this study showed that DNA-PKcs and P-gp were markedly elevated in $\mathrm{CD} 133^{+}$MG- 63 cells, which may explain the chemoresistance of these cells with a higher $\mathrm{IC}_{50}$. In contrast, as the expression of DNA-PKcs was downregulated by siRNA, P-gp and ABCB1 gene expression levels were significantly decreased. This indicates that, besides DNA damage repair, DNA-PKcs is involved in chemoresistance via the regulation of P-gp expression. Therefore, the molecular mechanism through which DNA-PKcs mediates P-gp expression needs to be further investigated.

The PI3K/Akt signaling pathway is an important mediator of cell growth, survival and motility. Dysregulation of the 
PI3K/Akt pathway is implicated in resistance to chemotherapy in a wide variety of neoplasias (27-29). Activated Akt targets many proteins, including I $\mathrm{B}$ kinase (IKK) which is responsible for the phosphorylation and degradation of $\mathrm{I} \kappa \mathrm{B}$. Then $\mathrm{NF}-\kappa \mathrm{B}$ is released from the I $\mathrm{B}$-bound complex. With $\mathrm{NF}-\kappa \mathrm{B}$ nuclear translocation and binding to its recognition sites, ABCB1 gene promoter activation is enhanced and gene expression is induced $(13,30)$. It has been demonstrated that downregulation of $\mathrm{NF}-\kappa \mathrm{B}$ inhibits $\mathrm{P}-\mathrm{gp}$ expression by blocking ABCB1 gene transcription (31-33). These findings suggest that the $\mathrm{Akt} / \mathrm{NF}-\kappa \mathrm{B}$ pathway may be able to mediate P-gp expression. Moreover, DNA-PKcs is a member of the PIKK family and is involved in Akt/NF- $\kappa \mathrm{B}$ pathway activation (18). Therefore, we postulate that DNA-PKcs is involved in P-gp expression via the Akt/NF- $\kappa \mathrm{B}$ pathway in $\mathrm{CD} 133^{+} \mathrm{MG}-63$ cells.

To verify our hypothesis, the relationship between the Akt/NF- $\kappa \mathrm{B}$ pathway and $\mathrm{P}$-gp expression was first investigated. Our results revealed that p-Akt and p-NF- $\mathrm{B} / \mathrm{p} 65$ were highly expressed and $\mathrm{NF}-\kappa \mathrm{B} / \mathrm{p} 65$ was mainly localized in the nuclei in the $\mathrm{CD}_{133^{+}}$cells compared with the CD133- cells, which indicated that the Akt/NF- $\mathrm{B}$ pathway was activated in these cells. The results are consistent with previous reports $(34,35)$. However, inhibition of the $\mathrm{Akt} / \mathrm{NF}-\kappa \mathrm{B}$ pathway via inhibition of Akt activity or downregulation of $\mathrm{NF}-\kappa \mathrm{B} / \mathrm{p} 65$ decreased $\mathrm{P}-\mathrm{gp}$ and $\mathrm{ABCB} 1$ gene expression. These results demonstrated that the $\mathrm{Akt} / \mathrm{NF}-\kappa \mathrm{B}$ pathway was involved in $\mathrm{P}-\mathrm{gp}$ expression in the $\mathrm{CD} 133^{+} \mathrm{MG}-63$ cells.

Since P-gp expression was decreased following downregulation of DNA-PKcs in the $\mathrm{CD}_{133}{ }^{+} \mathrm{MG}-63$ cells, we downregulated the DNA-PKcs expression via siRNA and examined the activation of the $A k t / N F-\kappa B$ pathway and $P-g p$ expression. The results showed that p-Akt (S473), p-IкB- $\alpha$, $\mathrm{p}-\mathrm{NF}-\kappa \mathrm{B} / \mathrm{p} 65, \mathrm{P}-\mathrm{gp}$ and ABCB1 gene were decreased after transfection of siDNA-PKcs in the CD133 ${ }^{+}$MG-63 cells, which demonstrated that downregulation of DNA-PKcs decreased P-gp expression at the mRNA and protein levels via suppression of the Akt/NF- $\kappa$ B pathway in these cells. The results were supported by a previous report that DNA-PKcs mediated Akt/NF- $\mathrm{B}$ pathway activation followed by the expression of P-gp in multidrug-resistant glioblastoma cells (36).

In addition, we found that disruption of DNA-PKcs decreased the expression of p-Akt (S473) rather than p-Akt (T308). This suggests that, as a member of the PIKK family, DNA-PKcs phosphorylates Akt at Ser473 specifically, which is consistent with previous data reported in other studies (37-39). This can be attributed to the fact that Ser473 is located in a hydrophobic motif Phe-Xaa-Xaa-Phe-Ser-Tyr (Xaa is any amino acid) in the $\mathrm{C}$ terminus, and DNA-PKcs has predisposition for phosphorylation sites at the extreme terminus of its substrate, which is critical for DNA-PK activity $(38,40)$.

$\mathrm{CD}_{133^{+}}$OS cells which are well-known as CSCs play important role in drug resistance. Our study presented evidence that DNA-PKcs and P-gp were significantly elevated and the Akt/NF- $\kappa$ B pathway was activated in the CD133 ${ }^{+}$MG-63 cells. Moreover, downregulation of DNA-PKcs decreased $\mathrm{P}$-gp expression and chemoresistance to CDDP via suppression of the Akt/NF- $\kappa \mathrm{B}$ pathway in these cells. We therefore propose that combining DNA-PKcs inhibition targeting CSCs with conventional chemotherapeutic agents may be considered as a strategy to improve the treatment outcome of OS.

\section{Acknowledgements}

This study was funded by the National Natural Science Foundation of China (81172551) and the Natural Science Foundation of Shandong Province of China (ZR2011HM037).

\section{References}

1. Whelan J, McTiernan A, Cooper N, Wong YK, Francis M, Vernon S and Strauss SJ: Incidence and survival of malignant bone sarcomas in England 1979-2007. Int J Cancer 131: E508-E517, 2012.

2. Sakamoto A and Iwamoto Y: Current status and perspectives regarding the treatment of osteo-sarcoma: Chemotherapy. Rev Recent Clin Trials 3: 228-231, 2008.

3. Chou AJ and Gorlick R: Chemotherapy resistance in osteosarcoma: Current challenges and future directions. Expert Rev Anticancer Ther 6: 1075-1085, 2006.

4. Allison DC, Carney SC, Ahlmann ER, Hendifar A, Chawla S, Fedenko A, Angeles C and Menendez LR: A meta-analysis of osteosarcoma outcomes in the modern medical era. Sarcoma 2012: 704872, 2012.

5. Miller BJ, Cram P, Lynch CF and Buckwalter JA: Risk factors for metastatic disease at presentation with osteosarcoma: An analysis of the SEER database. J Bone Joint Surg Am 95: e89, 2013.

6. Qiu H,Fang X, Luo Q and Ouyang G: Cancer stem cells: A potential target for cancer therapy. Cell Mol Life Sci 72: 3411-3424, 2015.

7. Tirino V, Desiderio V, d'Aquino R, De Francesco F, Pirozzi G, Graziano A, Galderisi U, Cavaliere C, De Rosa A, Papaccio G, et al: Detection and characterization of $\mathrm{CD}_{133^{+}}$cancer stem cells in human solid tumours. PLoS One 3: e3469, 2008.

8. Tirino V, Desiderio V, Paino F, De Rosa A, Papaccio F, Fazioli F, Pirozzi G and Papaccio G: Human primary bone sarcomas contain $\mathrm{CD}_{133^{+}}$cancer stem cells displaying high tumorigenicity in vivo. FASEB J 25: 2022-2030, 2011.

9. Li J, Zhong XY, Li ZY, Cai JF, Zou L, Li JM, Yang T and Liu W: CD133 expression in osteosarcoma and derivation of $\mathrm{CD} 133^{+}$ cells. Mol Med Rep 7: 577-584, 2013.

10. Li X, Tian J, Bo Q, Li K, Wang H, Liu T and Li J: Targeting DNA-PKcs increased anticancer drug sensitivity by suppressing DNA damage repair in osteosarcoma cell line MG63. Tumour Biol 36: 9365-9372, 2015.

11. Tian J, Li X, Si M, Liu T and Li J: CD271 ${ }^{+}$osteosarcoma cells display stem-like properties. PLoS One 9: e98549, 2014.

12. Choi BH, Kim CG, Lim Y, Shin SY and Lee YH: Curcumin down-regulates the multidrug-resistance mdrlb gene by inhibiting the PI3K/Akt/NF kappa B pathway. Cancer Lett 259: 111-118, 2008.

13. Kuo MT, Liu Z, Wei Y, Lin-Lee YC, Tatebe S, Mills GB and Unate $\mathrm{H}$ : Induction of human MDR1 gene expression by 2-acetylaminofluorene is mediated by effectors of the phosphoinositide 3-kinase pathway that activate NF-kappaB signaling. Oncogene 21: 1945-1954, 2002.

14. Cooke SL, Ng CK, Melnyk N, Garcia MJ, Hardcastle T, Temple J, Langdon S, Huntsman D and Brenton JD: Genomic analysis of genetic heterogeneity and evolution in high-grade serous ovarian carcinoma. Oncogene 29: 4905-4913, 2010.

15. Hanahan D and Weinberg RA: Hallmarks of cancer: The next generation. Cell 144: 646-674, 2011.

16. Xing J, Wu X, Vaporciyan AA, Spitz MR and Gu J: Prognostic significance of ataxia-telangiectasia mutated, DNA-dependent protein kinase catalytic subunit, and Ku heterodimeric regulatory complex 86-kD subunit expression in patients with nonsmall cell lung cancer. Cancer 112: 2756-2764, 2008.

17. Willmore E, Elliott SL, Mainou-Fowler T, Summerfield GP, Jackson GH, O'Neill F, Lowe C, Carter A, Harris R, Pettitt AR, et al: DNA-dependent protein kinase is a therapeutic target and an indicator of poor prognosis in B-cell chronic lymphocytic leukemia. Clin Cancer Res 14: 3984-3992, 2008.

18. Fang Y, Chai Z, Wang D, Kuang T, Wu W and Lou W: DNA-PKes deficiency sensitizes the human hepatoma HepG2 cells to cisplatin and 5-fluorouracil through suppression of the PI3K/Akt/NF- $\mathrm{BB}$ pathway. Mol Cell Biochem 399: 269-278, 2015.

19. Ciszewski WM, Tavecchio M, Dastych J and Curtin NJ: DNA-PK inhibition by NU7441 sensitizes breast cancer cells to ionizing radiation and doxorubicin. Breast Cancer Res Treat 143: 47-55, 2014. 
20. Facchino S, Abdouh M, Chatoo W and Bernier G: BMI1 confers radioresistance to normal and cancerous neural stem cells through recruitment of the DNA damage response machinery. J Neurosci 30: 10096-10111, 2010.

21. Mimeault M, Hauke R and Batra SK: Recent advances on the molecular mechanisms involved in the drug resistance of cancer cells and novel targeting therapies. Clin Pharmacol Ther 83: 673-691, 2008

22. Ye S, Zhang J, Shen J, Gao Y, Li Y, Choy E, Cote G, Harmon D, Mankin H, Gray NS, et al: NVP-TAE684 reverses multidrug resistance (MDR) in human osteosarcoma by inhibiting P-glycoprotein (PGP1) function. Br J Pharmacol 173: 613-626, 2016.

23. Yang X, Yang P, Shen J, Osaka E, Choy E, Cote G, Harmon D, Zhang Z, Mankin H, Hornicek FJ, et al: Prevention of multidrug resistance (MDR) in osteosarcoma by NSC23925. Br J Cancer 110: 2896-2904, 2014.

24. Fanelli M, Hattinger CM, Vella S, Tavanti E, Michelacci F, Gudeman B, Barnett D, Picci P and Serra M: Targeting ABCB1 and $\mathrm{ABCC} 1$ with their specific inhibitor CBT- $1{ }^{\circledR}$ can overcome drug resistance in osteosarcoma. Curr Cancer Drug Targets 16: 261-274, 2016.

25. Martins-Neves SR, Lopes AO, do Carmo A, Paiva AA, Simões PC, Abrunhosa AJ and Gomes CM: Therapeutic implications of an enriched cancer stem-like cell population in a human osteosarcoma cell line. BMC Cancer 12: 139, 2012.

26. Gonçalves C, Martins-Neves SR, Paiva-Oliveira D, Oliveira VE, Fontes-Ribeiro C and Gomes CM: Sensitizing osteosarcoma stem cells to doxorubicin-induced apoptosis through retention of doxorubicin and modulation of apoptotic-related proteins. Life Sci 130: 47-56, 2015.

27. Yang X, Fraser M, Moll UM, Basak A and Tsang BK: Akt-mediated cisplatin resistance in ovarian cancer: Modulation of p53 action on caspase-dependent mitochondrial death pathway. Cancer Res 66: 3126-3136, 2006.

28. Molina JR, Hayashi Y, Stephens C and Georgescu MM: Invasive glioblastoma cells acquire stemness and increased Akt activation. Neoplasia 12: 453-463, 2010.

29. Wittig-Blaich SM, Kacprzyk LA, Eismann T, BewerungeHudler M, Kruse P, Winkler E, Strauss WS, Hibst R, Steiner R, Schrader M, et al: Matrix-dependent regulation of AKT in Hepsin-overexpressing PC3 prostate cancer cells. Neoplasia 13: 579-589, 2011

30. Zhou G and Kuo MT: NF-kappaB-mediated induction of mdrlb expression by insulin in rat hepatoma cells. J Biol Chem 272: 15174-15183, 1997.
31. Sun J, Yeung CA, Co NN, Tsang TY, Yau E, Luo K, Wu P, Wa JC, Fung KP, Kwok TT, et al: Clitocine reversal of P-glycoprotein associated multi-drug resistance through down-regulation of

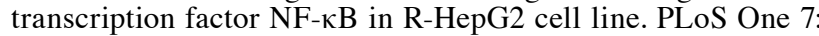
e40720, 2012.

32. Zhao BX, Sun YB, Wang SQ, Duan L, Huo QL, Ren F and Li GF: Grape seed procyanidin reversal of p-glycoprotein associated multi-drug resistance via down-regulation of NF- $\kappa \mathrm{B}$ and MAPK/ERK mediated YB-1 activity in A2780/T cells. PLoS One 8: e71071, 2013.

33. Xia YZ, Ni K, Guo C, Zhang C, Geng YD, Wang ZD, Yang L and Kong LY: Alopecurone B reverses doxorubicin-resistant human osteosarcoma cell line by inhibiting P-glycoprotein and NF-kappa B signaling. Phytomedicine 22: 344-351, 2015.

34. Nomura A, Banerjee S, Chugh R, Dudeja V, Yamamoto M, Vickers SM and Saluja AK: CD133 initiates tumors, induces epithelial-mesenchymal transition and increases metastasis in pancreatic cancer. Oncotarget 6: 8313-8322, 2015.

35. Zhu Y, Yu J, Wang S, Lu R, Wu J and Jiang B: Overexpression of CD133 enhances chemoresistance to 5-fluorouracil by activating the PI3K/Akt/p70S6K pathway in gastric cancer cells. Oncol Rep 32: 2437-2444, 2014.

36. Xi G, Hayes E, Lewis R, Ichi S, Mania-Farnell B, Shim K, Takao T, Allender E, Mayanil CS and Tomita T: CD133 and DNA-PK regulate MDR1 via the PI3K- or Akt-NF- $\mathrm{B}$ pathway in multidrug-resistant glioblastoma cells in vitro. Oncogene 35: 241-250, 2016.

37. Stronach EA, Chen M, Maginn EN, Agarwal R, Mills GB, Wasan $\mathrm{H}$ and Gabra $\mathrm{H}$ : DNA-PK mediates AKT activation and apoptosis inhibition in clinically acquired platinum resistance. Neoplasia 13: 1069-1080, 2011.

38. Feng J, Park J, Cron P, Hess D and Hemmings BA: Identification of a PKB/Akt hydrophobic motif Ser-473 kinase as DNA-dependent protein kinase. J Biol Chem 279: 41189-41196, 2004.

39. Rajagopalan S, Moyle MW, Joosten I and Long EO: DNA-PKcs controls an endosomal signaling pathway for a proinflammatory response by natural killer cells. Sci Signal 3: ra14, 2010.

40. Leslie NR,Biondi RM and Alessi DR: Phosphoinositide-regulated kinases and phosphoinositide phosphatases. Chem Rev 101: 2365-2380, 2001. 